\title{
CHANGE IN FREE TO TOTAL PROSTATE SPECIFIC ANTIGEN RATIO FOLLOWING TRANSURETHRAL RESECTION OF PROSTATE IN PATIENT WITH BENIGN PROSTATIC HYPERPLASIA
}

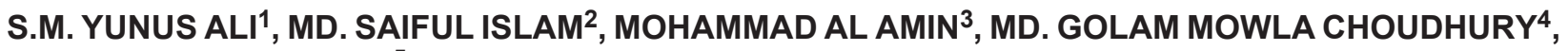 \\ ISTEAQ AHMED SHAMIM ${ }^{5}$
}

${ }^{1}$ Dept. of Urology, BSMMU, ${ }^{2}$ Dept. of Urology, BSMMU, ${ }^{3}$ Dept. of Urology, BSMMU, ${ }^{4}$ Dept. of Urology, BSMMU, ${ }^{5}$ Dept. of Urology, BSMMU, Dhaka

\begin{abstract}
Objective- To determine the changes in free to total serum prostate specific antigen (PSA) ratio level after transurethral resection of prostate (TURP) in BPH patients at different interval of time.

Materials \& Methods- $A$ total of 93 patients undergoing TURP for benign enlargement of prostate were included in the study. Serum total PSA and free PSA were assessed before operation and on the $I^{\text {st }}$ and $7^{\text {th }}$ postoperative day and at month 3 to determine the changes in total PSA, free PSA and free to total PSA ratio following TURP.

Result- The preoperative mean total PSA, free PSA and free to total PSA ratio were 3.5 $: L 1.7 \mathrm{ng} / \mathrm{ml}, 0.7810 .21 \mathrm{ng} / \mathrm{ml}$ and $0.28+0.07$. In terms of IPSS, 75(80.7\%) patients had severe lower urinary tract obstruction and 18(19.3\%) moderate obstruction. Histopathological examination of the resected prostatic tissue revealed that all the 93 patients had benign prostatic lesion.

Conclusion-The free and total PSA in first few days increases and thereafter it decreases in 3 months period following transurethral resection of prostate in men with $\mathrm{BPH}$. As both these parameters decrease proportionately, the free to total PSA ratio remains consistent. If free to total PSA ratio decreases it raises suspicision about the early changes in malignancy.
\end{abstract}

Key Wards: Total PSA, Free PSA, Free to total PSA ratio, BPH, TURP.

Bangladesh J. Urol. 2015; 18(2): 83-87

\section{Introduction}

Prostate specific antigen (PSA) is a glycoprotein produced by the cells of the prostate gland. It is present in small quantities in the serum of normal men, and is often elevated in the presence of prostate cancer and in other disorders of prostate. Rising levels of PSA over time are associated with both localized and metastatic prostate cancer $(\mathrm{CaP})[1]$.

Prostate specific antigen (PSA) is a tumor marker whose role in the diagnosis and follow-up of patients with prostatic diseases has continuously evolved. PSA behavior after transurethral resection of the prostate is crucial during patient follow-up. It is known that serum

Correspondence: SM Yunus Ali, Medical Officer, Dept. of Urology, BSMMU, Dhaka, E-mail: dryunusuro@gmail.com total PSA and free PSA levels increase temporarily in the first few days following a TURP procedure, decreasing gradually afterwards and stabilizes within 3-6 months[2]. However, free to total serum PSA ratio do not any change after TURP. Serum total PSA and free PSA level stabilization apparently depends on several factors, namely, patient's age, PSA levels before surgery, prostate volume and volume of resected prostatic tissue. Thus, there is no established cutoff value for normal PSA in patients who undergo TURP[3].

It was noted that patients who developed prostate carcinoma after TURP for BPH stabilized their PSA levels above $2.0 \mathrm{ng} / \mathrm{mL}$ - Thus, they proposed that patients with either PSA $>2.0 \mathrm{ng}(\mathrm{mL}$ or an early rise in total PSA and free PSA following TURP should be checked for prostate cancer[4]. 
Serum total PSA, free PSA and free to total PSA ratio is important for the diagnosis and follow-up of prostatic diseases. In the past few years, great importance has been put to free PSA, which is usually reduced in patients remain stable after TURP in patients with benign prostatic hyperplasia[5,6].

The role of prostatic inflammation, particularly its impact on PSA levels in the postoperative period is not clearly understood. Although many studies suggest that the presence of prostatic inflammation can contribute to increasing total PSA levels, the mechanism by which such histological changes induce the prostatic acinus marker to move to the systemic circulation is still controversial[7]. However, what changes in the serum PSA level takes place following TURP is important.

As the serum PSA level is known to be related with the types of prostatic lesions and volume of prostrate. After a TURP in patients with benign prostatic hyperplasia, decrease in the both serum total and free PSA level is expected. It is noted that patients after a TURP for BPH their total PSA, free PSA level not reduces significantly harboring malignancy in the prostate could be suspected, despite the histopathology report of resected prostatic chips reveals benign lesion of the prostate. Then repeat biopsy should be recommended for early diagnosis of the suspicious lesion of the Prostate and subsequent management. So the study of the changes in serum total PSA, free PSA and free to total PSA ratio is utmost important to early diagnosis, management and follow up of suspected prostatic lesion, for which TURP was performed in $\mathrm{BPH}$ patient.

Because of the controversy surrounding the changes in serum total PSA, free PSA and free to total ratio following TURP, a study was needed in the context of population of Bangladesh with a hypothesis as; Free to total prostate specific antigen (PSA) ratio remains consistent in benign enlargement of prostate following transurethral resection of prostate (TURP).

Such a study is considered important to aid in screening how many of the BPH patients have already had cancer cells. To this end the present study is proposed to evaluate the changes in serum total PSA, free PSA and free to total PSA ratio as a guideline for early detection of the prostate cancer after TURP.

\section{Patients and Methods}

The study was a prospective and observational study conducted from July 2009 to June 2010 with the permission of the Ethical Committee and was carried out in the Department of Urology, Sir Salimullah Medical College \& Mitford Hospital, Dhaka, Bangladesh.

The study population was male patients suffering from benign enlargement of prostate. Pre-operative assessment of the patients included clinical history, digital rectal examination (DRE) of the prostate, the international prostate symptom score (IPSS), prostate volume (by trans-rectal ultrasound), uroflowmetry and determination of serum total PSA, free PSA and free to total PSA ratio which was considered as a base line PSA values.

A total 93 patients were included in this study with mean age of 64 years (range: 50 to 85 years). All patients underwent Transurethral Resection of Prostate (TURP) procedure.

The weight of the resected prostatic tissue was recorded by weight measuring instruments and all resected prostatic chips were sent for histopathological examination. Benign prostatic hyperplasia(BPH) was confirmed by histopathological examination of resected prostatic chips. Every patient was followed up for day 1 , day 7 and at the end of month 3 after TURP with measurement of serum total PSA, free PSA and free to total PSA ratio.

The patient with age range of 50 to 85 years, symptomatic $\mathrm{BPH}$, history of failure of prior medical therapy, refractory urinary retention due to $\mathrm{BPH}$, significant obstruction due to enlarged prostate, moderate and severe international prostate symptoms score, and on digital rectal examination, prostate was enlarge were included in the study.

Patients with previous prostatic operation, pyuria and symptomatic urinary tract infection, recent urological manipulation such as prostatic biopsy in the last six weeks, neurological diseases that could have an impact on the urinary tract, under treatment of anti androgenic drugs for last 6 months and diagnosed cases of carcinoma of prostate were excluded from the study.

The data for study were collected using a structured questionnaire form and Statistical analysis were processed and analyzed using computer software SPSS (Statistical Package for Social Sciences) version 11.5. The test statistics used to analyses the data were paired t-test and Repeated Measure ANOVA. To compare the changes in serum PSA at different time interval (day 1 , day 7 and at 3 month) following Transurethral Resection of Prostate (TURP), repeated measure ANOVA statistics was used. For analytical tests level of significance was 
set at 0.05 and $p<0.05$ considered statistically significant. The results were presented in the form table and charts with due interpretation.

\section{Result}

About $30 \%$ of patients was below 60 years, $37.6 \%$ in the range of $60-70$ years and $33.3 \% 70$ or more than 70 years of age. The mean age was $63.9 \pm 9.5$ years and the minimum and maximum ages were 50 and 85 years respectively. Sixty four (69\%) of 93 exhibited hugely enlarged prostate on DRE, $20 \%$ moderately enlarged and the rest $11 \%$ mildly enlarged. The mean baseline total PSA, free PSA, and free to total PSA were $3.5 \pm 1.7 \mathrm{ng} / \mathrm{ml}, 0.78 \pm 0.21 \mathrm{ng} / \mathrm{ml}$ and $0.22 \pm 0.07$ $\mathrm{ng} / \mathrm{ml}$ respectively. (Table-I).

Table - I

The baseline PSA levels of the study patients $(n=93)$

\begin{tabular}{lcc}
\hline Baseline PSA & Mean \pm SD & Ranges \\
\hline Total PSA ng ml & $3.5 \pm 1.7$ & $0.99-6.0$ \\
Free PSA ng ml & $0.78 \pm 0.21$ & $0.23-3.7$ \\
Free to Total PSA & $0.22 \pm 0.07$ & $0.10-0.6$ \\
\hline
\end{tabular}

The maximum urinary flow rate and weight of the prostate before operation were $6.5-\mathrm{L} 1.5 \mathrm{ml} / \mathrm{sec}$ and $57.1 \pm 12.3$ gm respectively. In terms of baseline IPSS, $75(80.7 \%)$ patients had severe lower urinary tract obstruction and $18(19.3 \%)$ moderate obstruction. About $56 \%$ of the patients resected prostate weighted 30 or less then $30 \mathrm{~g}$ and $44.1 \%$ more than $30 \mathrm{gm}$. The mean weight of resected prostate was $31.5 \pm 10.4$ and the lowest and highest weights were $10 \mathrm{gm}$ and $55 \mathrm{gm}$ respectively. The histopathological examination of the resected prostatic tissue revealed that all the 93 patients had benign prostatic lesion. The change in total PSA, free PSA, and free to total PSA ratio at different time interval following resection of prostate varied. At the baseline the mean total and free PSA were $3.5 \mathrm{ng} / \mathrm{ml}$ and 0.78 $\mathrm{ng} / \mathrm{ml}$ respectively. Following resection of prostate both of them increased insidiously up to day one and than began to decline to become $2.8 \mathrm{ng}-\mathrm{ml}$ and $0.70 \mathrm{ng} / \mathrm{ml}$ respectively at the end of day 7 and to $1.9 \mathrm{ng}-\mathrm{ml}$ and $0.49 \mathrm{ng} / \mathrm{ml}$ at the end of months 3 . The free to total PAS ratio did not experience any significant change throughout the period of observation (Table- II).
Table - II

Comparison of PSA at different time interval

\begin{tabular}{lcccc}
\hline PSA & \multicolumn{4}{c}{ Time Interval } \\
\cline { 2 - 5 } & Baseeline & Day-1 & Day-7 & Month 3 \\
\hline $\begin{array}{l}\text { Total PSA } \\
\text { (ng-ml) }\end{array}$ & $3.5 \pm 1.7$ & $4.2 \pm 1.8$ & $2.8 \pm 1.6$ & $1.9 \pm 0.5$ \\
$\begin{array}{l}\text { Free PSA } \\
\text { (ng-ml) }\end{array}$ & $0.78 \pm 0.21$ & $1.0 \pm 0.4$ & $0.70 \pm 0.30$ & $0.49 \pm 0.11$ \\
$\begin{array}{l}\text { Free Total } \\
\text { PSA ratio }\end{array}$ & $0.22 \pm 0.07$ & $0.23 \pm 0.04$ & $0.23 \pm 0.08$ & $0.25 \pm 0.03$ \\
\hline
\end{tabular}

\section{Discussion}

PSA is a valuable tool in diagnosing prostatic disorders and evaluating prognosis, but there is dispute regarding its changes following TURP, which probably depends on several factors. One of the first published studies evaluating the impact of TURP on PSA levels, found a correlation between prostate size and preoperative total PSA and free PSA noting that there is a temporary rise in total PSA and free PSA levels in the first few days following surgery[6]. Similar results was published, suggesting that one should wait four to six weeks after TURP to make new PSA measurements[8]. A study with 190 patients with $\mathrm{BPH}$ found measured PSA levels before surgery and three months after TURP in Mean PSA decreased by $70 \%[2]$.

The present study demonstrated that the mean total PSA, free PSA and free to total PSA ratio were $3.5 \pm$ $1.7 \mathrm{ng} / \mathrm{ml}, 0.78 \pm 0.21 \mathrm{ng} / \mathrm{ml}$ and $0.28 \pm 0.07$ respectively. Following transurethral resection of prostate (TURP) total PSA and free PSA were significantly increased 1 day after intervention than those before intervention ( $3.5 \pm$ 1.7 vs. $4.2 \pm 1.8$ vs., $p<0.001$ and $0.78 \pm 0.21$ vs. $1.0 \pm$ $0.4, p<0.001$ respectively), though free to total PSA ratio did not experience any change. It was reported similar findings with total and free PSA levels increased significantly on first postoperative day compared to the preoperative values $(p<0.05)$. However, free to total PSA ratio was not changed significantly after the transurethral resection of prostate (TURP) $(p>0.05)$ [9].

In our study total PSA and free PSA began to decrease after 7 days of resection of the prostate as compared to base line values $(2.8 \pm 1.6$ vs $3.5 \pm 1.7$ and $.70 \pm .30$ vs.78A:.21 respectively)- Although total PSA and free PASA ratio did not exhibit any significant changes during

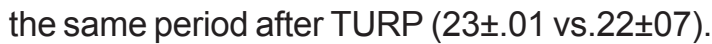


At the end of month 3, total PSA and free PSA both subsided significantly compared to their baseline figure $(1.9-10.5$ vs. $3.511 .7, p<0.001$ and $0.49 \pm 0.11$ vs. $0.78 \pm 0.21, p<0.001$ respectively). However, free-total PSA ratio did not experience any significant change during the same period of observation $(0.22 \pm 0.07$ vs$0.25 \pm 0.03, p=0.191$ ).

A similar study was conducted to evaluate the outcome 6 months after TURP was that serum total PSA and free PSA were significantly reduced, but the free-to-total PSA ratio remained consistent as before 'ruRP. On the basis of their findings they suggested that if free to total PSA ratio, instead of remaining consistent, decreased gradually it should be taken as a sign of early malignancy and physicians should keep constant vigilance on those patients with further investigations to reach to a conclusive diagnosis[10].

It was reported that mean total PSA to be $1.61 \pm .89 \mathrm{ng} /$ $\mathrm{ml}, 1.47 \pm 0.83 \mathrm{ng} / \mathrm{ml}, 1.57 \pm 0.88 \mathrm{ng} / \mathrm{ml}$ at 1 hour, $24^{\mathrm{h}}$ hour and $21^{\text {th }}$ day respectively. The mean free PSA was $0.67 \pm 0.43 \mathrm{ng} / \mathrm{ml}$ at 1 hour, $0.63-\mathrm{t} 0.45 \mathrm{ng} / \mathrm{ml}$ at 24th hours and $0.75 \pm 0.45 \mathrm{ng} / \mathrm{ml} 21^{\text {st }}$ days[11].

It was reported that mean total PSA declined $71 \%$ after TURP and 60 days after surgery the reduction reached its lowest and stabilizing thereafter $(6.19+7.06 \mathrm{ng} / \mathrm{ml}$ before surgery to $1.75+1.66 \mathrm{ng} / \mathrm{ml}$ on day $60, \mathrm{p}<$ $0.001)$. The mean baseline free to total PSA ratio was $18.2 \%+3.4 \%$ and was not significantly changed at any given time point in the postoperative period $(p=0$ 91)- There were also no statistically significant differences in total PSA or free to total PSA ratio between patients with and without prostatitis at any time point $(p$ $=0.23)[12]$.

Contrasting with the findings of our study, Cetinkaya (1999)[13] reported that postoperative total PSA and free PSA increased significantly in 1" 7 days compared with preoperative values $(p<0.001$ and $P=0.024$, respectively), although the difference between preoperative and postoperative free to total PSA ratios was not statistically significant $(p=0.103)$.

Another study reported that $2.93 \mathrm{ng} / \mathrm{ml}$ which tended to increase at I month after the operation ( $3.18 \mathrm{f} 3.23 \mathrm{ng} /$ $\mathrm{ml}, \mathrm{p}=0.032$ ) but decreased in the next 2 months and became stabilized at $1.79 \pm 1.82 \mathrm{ng} / \mathrm{ml}$ after 6 months $(p<0.001)$. In our study we also observed a significant reduction of total and free PSA in 3 months observation favouring the findings of the present study, but in our study both these parameters began declining after $7 \mathrm{~h}$ postoperative day which not consistent with findings of Shim et al (2010)[14].

In our study as well the free to total PSA ratio did not experience any change following TURP, but in two cases the mean free to total PSA ratio decreased insidiously from 0.165 at baseline to 0.115 at the end of month 3 raising suspicion that those two cases might have malignancy.

\section{Conclusions}

From the findings of the study, it was concluded that both free and total PSA in first few days increases and thereafter it decreases in 3 months period following transurethral resection of prostate in men with $\mathrm{BPH}$. As both these parameters decrease proportionately, the free to total PSA ratio remains consistent. If free to total PSA ratio decreases it raises suspicion about the early changes in malignancy. So urologists after performing TURP for BPH should keep constant vigilance on their patients and advice regular check-up of free and total PSA and if free to total PSA decreases in any patient, he should be suspected of harboring malignancy.

Conflict of Interest : None declared

\section{References}

1. Andriole GL, Grubb RL \& Buys SS 2009, 'Mortality Results from a Randomized Prostate-Cancer Screening Trial', New Eng. J. Med.,vol.360,pp1310-

2. Aus G, BergdahI S, Frosing R, Lodding $1^{1}$, Pileblad E \& I lugosson J 19\%, 'Reference range of prostatespecific antigen after transurethral resection of the prostate', Urology, vol. 47, pp. 529-31.

3. Recker F, Kwiatkowski MK \& Petterson K 1998, 'Enhanced expression of prostate- specific antigen in the transition zone of the prostate. A characterization following prostatectomy for benign hyperplasia', Eur Urol, vol.3,pp.549-55.'

4. Wolff JM, Boekels 0, Borchers H, Jak-sc G, Rohde D 2000, 'Altered prostate specific antigen reference range after transurethral resection of the prostate', Anticancer Res, vol. 20, pp. 4977-80.

5. Recker F, Kwiatkowski MK, Pettersson K, 11 fironen T, Lummen G \& Huber A 1988, 'Enhanced expression of prostate-specific antigen in the transition zone of the prostate: A characterization following prostatectomy for benign hyperplasia', Eur Urol, vol. 33, pp. 549-55. 
6. Vcsey SG, Goble NM, Stower MI, Hammonds JC \& Smith PJ 1998, 'The effects of transurethral prostatectomy on serum prostate specific antigen', Br J Urol, vol. 62, pp. 347-51.

7. Khiel R, Lemos AD, Stavalle JN \& Ortiz V 2001, 'Correlation between chronic prostatitis and prostate-specific antigen values', Int Braz J Urol, vol. 27, pp. 42-5.

8. Oesterling JE, Tckchandani All, Martin SK, Bergstralh EJ, Reichstein E \& Diamandis EP 1996, 'The periurethral glands do not significantly influence the scrum prostate specific antigen concentration', J Urol, vol. I 55,pp. 1658-60.

9. Kim DW, Ryu DS \& Oh TI 1 2003, 'Effect of Transurethral Surgery on Serum Percent Free Prostate-Specific Antigen Levels', Korean J Urol, vol.44,no.3,pp.272-7.

10. Hwang TIS, Juang GD, Yeh $\mathrm{CH}$, Cheng YI 1, Chou KY \& Shen YY 2003, 'Free-to-total prostate specific (PSA) Ratio in Chinese Patients Who Underwent Transurethral Resection of Prostate', JTUA, vol.14, no. 1, pp-6-10.
11. Erdema E, Doruka E, Tungkirana A, Bilginb E, Ulusoya E \& Akbaya F, 2004, 'General anesthesia does not affect the serum complexed and free prostate specific antigen levels', Sw,i s Med Wely, vol.1 3 4,pp.4 06 - 9.

12. Fonseca RC, Gomes CM, Meireles EB, Freire GC \& Srougi M' 2008, 'Prostate specific antigen levels following transurethral resection of the prostate', Int Braz J Urol, vol.34: pp.41-8.

13. Cetinkaya M, Ulusoy E, Aki T, Koran M, Kundak C, Aydos MM \& G6kkaya S 1999, 'Effect of transurethral resection on serum frec/total prostatespecific antigen levels in patients with benign prostatic hyperplasia', Urology. Vol.53, no. I, pp. 118-20.

14. Shim M, Kwon T, Kim SC, Ha SH \& Alm TY 2010, 'Changes in Serum Prostate-Specific Antigen Levels after Potassium-Titanyl-Phosphate (KIT) Laser Vaporization of the Prostate', Korean J Urol, vol.51,no.2,pp.111-14.

Abbreviations:

BPH : Benign Prostatic Hyperplasia

PSA : Prostate Specific Antigen

TURP : Transurethral Resection of Prostate 